\title{
Molecular Testing and Future Prespective Method of nCOV-19
}

\author{
Akila $^{1}$, Anitha C. ${ }^{1}$, Pratheeba $\mathbf{J}^{2}$, Sumanth Kumar B. ${ }^{2}$ \\ ${ }^{1}$ Assistant Professor, Department of Microbiology, Meenakshi Medical College Hospital and Research Institute, \\ Enathur, Kanchipuram, Tamilnadu, India, ${ }^{2}$ Assistant Professor, Department of Biochemistry, Meenakshi Medical \\ College Hospital and Research Institute, Enathur, Kanchipuram, Tamilnadu, India
}

\begin{abstract}
A respiratory disease caused by the corona virus is SARS-CoV-2 spread from China to all over the world. The pathogen causes serious health hazards to humankind from infectious bats. The symptoms range from mild infection to serious problems and life threatening incidence occur globally. The testing method should be more rapid for correct diagnosis and clinical laboratories play a pivotal role in COVID-19 testing, providing presumptive diagnosis at the earliest and nucleic acid based amplification techniques such as RTqPCR delivering high fidelity reports. The rapid point-of-care testing is crucial in handling such emergency to enhance large-scale surveillance to aid quarantine of suspicious cases and thereby encasing the contagious spread. The review focuses on RT-qPCR and future method such as LAMP assay and nano based techniques are suggested for efficiency and to overcome the false results.
\end{abstract}

Keywords: RT-qPCR, Molecular method, LAMP, Corona 19, Respiratory infection.

\section{Introduction}

The pandemic situation caused by the virus genetic material is SSRNA which affects the host and the entire respiratory system, causing severe illness and leads to death ${ }^{[1]}$. In past years diseases like SARS and MERS ${ }^{[2]}$ showed this pandemic effect, causing death affecting thousands of people compared to this novel corona virus is more pathetic and entire world is affected by this harmful pathogen. The most worrisome is that there is no proper drug and scientists are showing tremendous work in identifying the vaccine and to prevent the disease. World Health Organization (WHO) named this virus as nCOV and later renamed as COVID-19 [3]. International Committee on Taxonomy of Virus (ICTV) later identifying the structural morphology of the virus and is currently called by the name of SARS-CoV-2 ${ }^{[4]}$.

\section{Corresponding Author:}

\section{Akila}

Assistant Professor, Department of Microbiology, Meenakshi Medical College Hospital and Research Institute, Enathur, Kanchipuram, Tamilnadu, India e-mail: akila@mmchri.ac.in
The virus belong to coronaviridae family and possesses 4 different genera's such as $\alpha, \beta, \gamma$ and $\Delta$ corona virus. The $\alpha$ and $\beta$ viruses were present in bats and $\gamma$ and $\Delta$ virus present in birds ${ }^{[5,6]}$. The virus has genetic material of single standard RNA, which is about $32 \mathrm{~kb}$ in length and largest human affecting RNA virus. The study focuses on the molecular techniques which can identify the $\mathrm{nCoV}$ more precisely. The aim of this technique is to gain knowledge among researchers in handling the molecular biotechnology as an essential medium.

\section{Molecular techniques in COVID-19 testing:}

Real-time RT-qPCR: Human corona virus (hCoVs) possesses minimum 10 open reading frames (ORFs) and the genetic material is similar to SARS-CoV-2. Out of $10 \mathrm{ORF}, \mathrm{ORF} 1 \mathrm{a} / \mathrm{b}$ has two large polyproteins with 16 proteins which are not in exact structure and forms the enzyme viral replicase transcripts in SARS-CoV as well as MERS-CoV [7]. The nucleic acid sequencing based techniques is advantageous over the other diagnostic investigations and are validated as confirmatory testing for COVID-19. The presence of viral SSRNA not only shows the presence of acute disease, since RNA traces decrease from $66.7 \%$ before day- 7 to $45.5 \%$ during the days $15^{\text {th }}$ to $39^{\text {th }}$ days of infection ${ }^{[8]}$. The negative test in patients should be more careful and repeated sample 
testing along with Chest imaging is very much helpful in tracking the records of severity of infection [9]. With certainty nucleic acid sequencing techniques is robust yet many difficulties remain such as damages that incur in SARS-CoV-2 target RNA during replicative processes and release of broken pieces of RNA into the bloodstream. These challenges can be overcome for isolation of RNA fragments using CRISPR or in combination with nano-based nucleic acid extraction.

COVID-19 testing by RT-qPCR is performed with labeled probes targeting either of ORF1 gene RNA dependent, N, E \& S genes. USA developed an RTqPCR diagnostic tool for identifying the corona viruses. For a patient to be confirmed positive, 3 reactions, focusing the $\mathrm{N}$ gene detect the virus and validated for the infection ${ }^{[10]}$. The Charite testing algorithm for SARSCoV-2 infection states that test assays detect target genes to be positive in order to progress through the next step. The second step would consist of testing with RT-qPCR targeting the virus specific to RdRp with quality control of Alpha and Beta corona viruses, since other SARSCoVs are not currently present in humans, the cases that are augmented and patients are true positives for the viral infection. Apart from these CT scan is highly recommended with false negative people. The possibility of false negatives by RT-qPCR tests with the patient's nucleic acid shows high probability of false result in the early stage of COVID-19 infection patients ${ }^{[9]}$.

The other persons viral RNA can be used as a positive control, the RdRp assay with two probes specific to the viruses and an additional probe that reacts only with novel CoV. By inhibiting the experiments, the probes react alone or in groups, show the same level of identification in each target virus. The assays were highly accurate with $95 \%$ detection probability and the copies per reaction have been identified. Similarly the $\mathrm{N}$ gene testing assay after ORF1b confirmation is a subgenus of Sarbeco virus ${ }^{[11]}$.

Multiplex RT-PCR: The multiplex PCR for the real-time pan-CoV detection, targeting four $\mathrm{HCoV}$ 229E, HKU1, NL63, and OC43 revealed the diagnostic problem arising through seasonal variation in $\mathrm{CoV}$ frequency, and also highlighted on the rate of coinfection ${ }^{[12]}$. Chu et al reported the use of two monoplex RT-qPCR assays in identifying the target gene regions of novel virus based on the sequence availability in Genbank along with those of CoV's, the assay was found to have detection limits below 10 copies per reaction
[11]. The presence of viral pathogen in respiratory tracts was detected by amplification of the virus, nucleocapsid protein genes fragments for a total of 4880 cases revealed $39.80 \%$ positivity for virus nucleocapsid protein and ORF1ab (40.98\%) ${ }^{[7]}$. The performance of QIAstat-Dx respiratory for the virus panel, which uses QIAstat-Dx cartridge permits direct insertion of the 66 NP specimens, was kept in transport medium without additional manipulation with testing activity comparable to that of the WHO suggestions. The RT-qPCR assay has a limitation of 1,000 copies $/ \mathrm{ml}$, and no crossreaction other hCoVs (229E, OC43, NL63 and HKU), other respiratory viruses ${ }^{[13]}$.

\section{Future prospective of COVID-19 testing:}

LAMP Assays: LAMP activity is based on the techniques of amplification of nucleic acid which is rapid and also amplifies target SARS-CoV-2 DNA with elevated specificity beneath isothermal conditions. Isothermal LAMP amplified a piece of ORF1ab gene; and synthesized a new RNA was equivalent to 10 copies of corona virus ${ }^{[14]}$. Random-amplification deepsequencing of the novel CoV by mNGS platform helps in determining its origin, evolutionary history and discrimination among MERS-CoV and SARS-CoV identification. For the investigative purposes, the genetic material performs molecular assay for the human corona virus while some type of $\mathrm{CoV}$ deteriorates many primer sets. The respiratory panel consisted of multiple sets of oligo nucleotide detected endemic human corona virus whereas target virus was not detected in these panels. Eleven molecular devices from various manufacturers approved for testing of SARS-CoV-2 revealed variable performances. MGI Tech and Innovita utilized the NGS technique to detect all the species along with SARS$\mathrm{CoV}-2$ and an isothermal amplification technique coupled with chip detection respectively, while the remaining nine devices utilized real-time technique for amplification and detection ${ }^{[15]}$.

Film array for respiratory virus pathogens: The ePlexRespiratory Pathogeninstrumentisa comprehensive system requiring no additional accessories and has a testing capacity ranging from 24 to 96 samples tested within $2 \mathrm{hrs}$ thus providing flexibility of testing in small spaced laboratories. An added advantage of this system includes the generation of customized information and possible for the two directional interface with information system of the laboratory. In a multicentre study, USA and Canada, evaluating the ePlex panel (GenMark 
Diagnostics) facilitated differentiation of four $\mathrm{CoV}$ genotypes with simultaneous detection of 19 different viruses. The ePlex offered a highly specific method of identification in microbial respiratory pathogens with $100 \%$ reproducibility and facilitates genotypes epidemic surveillance for better treatment strategies ${ }^{[16]}$.

Nano-based diagnostic techniques: The implication of nano materials with potential application into diagnostic tests is a critical tool for rapid screening of cases at-risk populations. A one-step reverse transcription with nanoparticles-based physiochemical detector, i.e. biosensor designed using 2 LAMP primer sets, F1ab and nasal pharynx genes of the virus concurrently identified both targets with sensitivity of 12 number of copies and there is no cross reaction generated from the viral templates ${ }^{[17]}$. Seo et al developed virus with a particular protein in spike which is coated with the sheets of graphene sheets possessing a detector for the novel virus in clinical samples ${ }^{[18]}$. The $2 \mathrm{D}$-gold nanochipbased plasmonic nucleic acid biosensor developed by Qui et al facilitated the detection of viral RNA up to $0.22 \mathrm{ppm}$ concentration using localized Surface Plasmon Resonance. A micro fluidic ELISA developed by Tan et al reported of quantitative, sensitive detection of the virus specific antibody and antigen in serum within a short period of 15-20 minutes ${ }^{[17]}$.

\section{Conclusion}

Health care workers are involved in tremendous efforts in global crisis to stop the spread of COVID-19 with their therapeutic plan as per the guidelines of WHO. Scientists were actively involved in treating the virus and developing new vaccines and therapies. Deeper knowledge and clinical tests are conducted all over the globe and countries join hands to prevent the spread and vaccinations are in trial till date. Thus, our study focuses on the molecular diagnostic tools to identify the virus more accurately to avoid false positive or negative cases to inhibit the pathogenic spread.

\section{Ethical Clearance: Nil}

Source of Funding: Meenakshi Academy of Higher Education and Research, Chennai, India

\section{Conflict of Interest: Nil}

\section{References}

1. Weiss SR, Leibowitz JL. Coronavirus pathogenesis. InAdvances in virus research 2011 Jan 1 (Vol. 81, pp. 85-164). Academic Press.

2. Lu R, Zhao X, Li J, Niu P, Yang B, Wu H, Wang W, Song H, Huang B, Zhu N, Bi Y. Genomic characterisation and epidemiology of 2019 novel coronavirus: implications for virus origins and receptor binding. The Lancet. 2020 Feb 22;395(10224):565-74.

3. World Health Organization. Coronavirus disease 2019 (COVID-19): situation report, 72.

4. Gorbalenya AE, Baker SC, Baric R, Groot RJ, Drosten C, Gulyaeva AA, Haagmans BL, Lauber C, Leontovich AM, Neuman BW, Penzar D. Severe acute respiratory syndrome-related coronavirus: The species and its viruses-a statement of the Coronavirus Study Group.

5. Li G, Fan Y, Lai Y, Han T, Li Z, Zhou P, Pan P, Wang W, Hu D, Liu X, Zhang Q. Coronavirus infections and immune responses. Journal of medical virology. 2020 Apr;92(4):424-32.

6. Lai MM, Holmes KV. Coronaviridae: the viruses and their replication Fields, BN Knipe, DM Howley, PM eds. Fields virology Lippincott-Raven Philadephia. 2001;1163:1185.

7. Hao Q, Wu H, Wang Q. Difficulties in False Negative Diagnosis of Coronavirus Disease 2019: A Case Report.

8. Zhao J, Yuan Q, Wang H, Liu W, Liao X, Su Y, Wang X, Yuan J, Li T, Li J, Qian S. Antibody responses to SARS-CoV-2 in patients of novel coronavirus disease 2019. Clinical Infectious Diseases. 2020 Jan 1.

9. Chu DK, Pan Y, Cheng SM, Hui KP, Krishnan P, Liu Y, Ng DY, Wan CK, Yang P, Wang Q, Peiris M. Molecular diagnosis of a novel coronavirus (2019-nCoV) causing an outbreak of pneumonia. Clinical chemistry. 2020 Apr 1;66(4):549-55.

10. Zhang W, Du RH, Li B, Zheng XS, Yang XL, Hu B, Wang YY, Xiao GF, Yan B, Shi ZL, Zhou P. Molecular and serological investigation of 2019$\mathrm{nCoV}$ infected patients: implication of multiple shedding routes. Emerging microbes \& infections. 2020 Jan 1;9(1):386-9.

11. Corman VM, Landt O, Kaiser M, Molenkamp R, Meijer A, Chu DK, Bleicker T, Brünink S, Schneider J, Schmidt ML, Mulders DG. Detection of 2019 novel coronavirus (2019-nCoV) by real-time RT-PCR. Eurosurveillance. 2020 Jan 23;25(3):2000045. 
12. Visseaux B, Le Hingrat Q, Collin G, Bouzid D, Lebourgeois S, Le Pluart D, Deconinck L, Lescure FX, Lucet JC, Bouadma L, Timsit JF. Evaluation of the QIAstat-Dx Respiratory SARS-CoV-2 Panel, the first rapid multiplex PCR commercial assay for SARS-CoV-2 detection. Journal of clinical microbiology. 2020 Apr 27.

13. Yu L, Wu S, Hao X, Li X, Liu X, Ye S, Han H, Dong X, Li X, Li J, Liu J. Rapid colorimetric detection of COVID-19 coronavirus using a reverse tran-scriptional loop-mediated isothermal amplification (RT-LAMP) diagnostic plat-form: iLACO. medRxiv. 2020 Jan 1.

14. Moriguchi T, Harii N, Goto J, Harada D, Sugawara H, Takamino J. \& Nakao, A.(2020). A first case of meningitis/encephalitis associated with SARSCoronavirus-2. International Journal of Infectious Diseases

15. Babady NE, England MR, Smith KL, He T, Wijetunge DS, Tang YW, Chamberland RR, Menegus M, Swierkosz EM, Jerris RC, Greene W. Multicenter evaluation of the ePlex respiratory pathogen panel for the detection of viral and bacterial respiratory tract pathogens in nasopharyngeal swabs. Journal of clinical microbiology. $2018 \mathrm{Feb}$ $1 ; 56(2)$.

16. Seo G, Lee G, Kim MJ, Baek SH, Choi M, Ku KB, Lee CS, Jun S, Park D, Kim HG, Kim SJ. Rapid detection of COVID-19 causative virus (SARSCoV-2) in human nasopharyngeal swab specimens using field-effect transistor-based biosensor. ACS nano. 2020 Apr 15;14(4):5135-42.

17. Lu R, Zhao X, Li J, Niu P, Yang B, Wu H, Wang W, Song H, Huang B, Zhu N, Bi Y. Genomic characterisation and epidemiology of 2019 novel coronavirus: implications for virus origins and receptor binding. The Lancet. 2020 Feb 22;395(10224):565-74.

18. Qiu G, Gai Z, Tao Y, Schmitt J, Kullak-Ublick GA, Wang J. Dual-functional plasmonic photothermal biosensors for highly accurate severe acute respiratory syndrome coronavirus 2 detection. ACS nano. 2020 Apr 13;14(5):5268-77. 